\title{
Suicide attempts, plans, and ideation in culturally diverse sites: the WHO SUPRE-MISS community survey
}

\author{
JOSÉ M. BERTOLOTE ${ }^{*}$, ALEXANDRA FLEISCHMANN ${ }^{1}$, DIEGO DE LEO ${ }^{2}$, \\ JAFAR BOLHARI ${ }^{3}$, NEURY BOTEGA ${ }^{4}$, DAMANI DE SILVA ${ }^{5}$, \\ HUONG TRAN THI THANH ${ }^{6}$, MICHAEL PHILLIPS ${ }^{7}$, LOURENS SCHLEBUSCH ${ }^{8}$, \\ AIRI VÄRNIK ${ }^{9}$, LAKSHMI VIJAYAKUMAR ${ }^{10}$ AND DANUTA WASSERMAN 11 \\ ${ }^{1}$ Department of Mental Health and Substance Abuse, World Health Organization, Geneva, Switzerland; \\ ${ }^{2}$ Australian Institute for Suicide Research and Prevention, Griffith University, Brisbane, Queensland, Australia; \\ ${ }^{3}$ Tehran Psychiatric Institute, Mental Health Research Centre, Tehran, Islamic Republic of Iran; \\ ${ }^{4}$ Department of Psychiatry, FCM - UNICAMP, Campinas, Brazil ; ${ }^{5}$ Department of Psychological Medicine, \\ Faculty of Medicine, University of Colombo, Sri Lanka $;{ }^{6}$ Hanoi Medical University, Dong Da, Hanoi, \\ Viet Nam; ${ }^{7}$ Beijing Suicide Research and Prevention Center, Beijing Hui Long Guan Hospital, Beijing, \\ People's Republic of China $;{ }^{8}$ Department of Behavioural Medicine, School of Family and Public Health \\ Medicine, Faculty of Health Sciences, Nelson R. Mandela School of Medicine, University of KwaZulu-Natal, \\ Durban, South Africa $;{ }^{9}$ Estonian-Swedish Mental Health and Suicidology Institute, Estonian Center of \\ Behavioral and Health Sciences, Tallinn, Estonia; ${ }^{10}$ Department of Psychiatry, Voluntary Health Services \\ \& SNEHA, Kotturpuram, Chennai, India; ${ }^{11}$ National and Stockholm County Centre for Suicide Research \\ and Prevention of Mental Ill-Health (NASP), Department of Public Health Sciences, Karolinska Institute \\ and Swedish National Institute of Psychosocial Medicine, Stockholm, Sweden
}

\begin{abstract}
Background. The objectives were to assess thoughts about suicide, plans to commit suicide and suicide attempts in the community, to investigate the use of health services following a suicide attempt, and to describe basic socio-cultural indices of the community.

Method. The community survey was one component of the larger WHO multisite intervention study on suicidal behaviours (SUPRE-MISS). In each site, it aimed at randomly selecting and interviewing at least 500 subjects of the general population living in the catchment area of the emergency department where the intervention component of the study was conducted. Communities of eight SUPRE-MISS sites (in Brazil, China, Estonia, India, Iran, South Africa, Sri Lanka, and Viet Nam) participated plus two additional sites from Australia and Sweden conducting similar surveys.
\end{abstract}

Results. Suicide attempts $(0 \cdot 4-4 \cdot 2 \%)$, plans $(1 \cdot 1-15 \cdot 6 \%)$, and ideation $(2 \cdot 6-25 \cdot 4 \%)$ varied by a factor of 10-14 across sites, but remained mostly within the ranges of previously published data. Depending on the site, the ratios between attempts, plans, and thoughts of suicide differed substantially. Medical attention following a suicide attempt varied between $22 \%$ and $88 \%$ of the attempts.

Conclusions. The idea of the suicidal process as a continuous and smooth evolution from thoughts to plans and attempts of suicide needs to be further investigated as it seems to be dependent on the cultural setting. There are indications, that the burden of undetected attempted suicide is high in different cultures; an improved response from the health sector on how to identify and support these individuals is needed.

* Address for correspondence: Dr José M. Bertolote, Department of Mental Health and Substance Abuse, World Health Organization, CH-1211, Geneva 27, Switzerland. (Email: bertolotej@who.int) 


\section{INTRODUCTION}

Mortality due to suicide has increased by $\sim 60 \%$ in some developed and developing countries over the last 45 years. In 2002, it was estimated that 877000 lives were lost due to suicide (WHO, 2003). In many countries, the highest suicide rates have shifted from the elderly towards younger persons in the 35-45 years age group, and even the 15-25 years age group in some places. Suicide is now among the five top causes of death for young adults of both sexes, worldwide.

Suicide rates are known for the majority of developed countries. However, in the absence of national statistics on suicide attempts virtually in all countries, little is known about the real dimension of the burden of attempted suicide on a global basis. Independent studies have indicated that depending on the place, suicide attempts can be up to 10-40 times more frequent than completed suicides (Platt et al. 1992; Schmidtke et al. 2004). The extent and type of suffering and burden associated with suicide attempts is by no means negligible. Selfinflicted injuries (including suicide attempts) represented $1.4 \%$ of the global burden of disease in 2002 (WHO, 2003) and are expected to increase to $2.4 \%$ in 2020 .

In selected catchment areas of 13 European countries, the highest average age-standardized rate recorded was $314 / 100000$ for males and 462/100 000 for females, between 1989 and 1992. The corresponding lowest rates were 45 and 69/100 000 respectively (Platt et al. 1992; Schmidtke et al. 2004).

While registration studies, such as the $\mathrm{WHO}$ EURO one, assess suicide attempts that are treated in the health system, surveys in population samples are used to study the prevalence of suicidal behaviour not registered by the health-care system.

In a cross-national comparison of the rates of suicide ideation and attempts Weissman et al. (1999) presented data of community household surveys conducted in the 1980s, using similar methods in nine countries (Canada, France, Lebanon, New Zealand, Puerto Rico, Republic of Korea, Taiwan, USA, and West Germany). The lifetime prevalence of suicide ideation varied between $2 \cdot 1 \%$ and $18 \cdot 5 \%$. For suicide attempts, the lifetime prevalence rates ranged from $0.7 \%$ to $5 \cdot 9 \%$. Further studies on lifetime prevalence of suicide ideation and attempts originated from Great Britain (Meltzer et al. 2002), Denmark (Kjoller \& Helweg-Larsen, 2000), USA (Schwab et al. 1972; Paykel et al. 1974; Moscicki, 1989; Kessler et al. 1999) and Australia (Pirkis et al. 2000), and revealed similar results; a review was published by Welch (2001).

The multisite intervention study on suicidal behaviours (SUPRE-MISS) was launched in 2000 by the World Health Organization to address the emerging public health problem of attempted suicide. The rationale of SUPREMISS was to increase the knowledge about suicidal behaviours and about effective interventions for suicide attempters in culturally diverse places. SUPRE-MISS has three components: (a) a randomized clinical trial to evaluate treatment strategies for suicide attempters seen at emergency-care departments in defined catchment areas; (b) a community survey to identify suicidal ideation and behaviour in the same catchment areas; and (c) a qualitative community description of the basic socio-cultural characteristics of the target communities.

This paper describes the results of the community survey which aimed to identify the prevalence of suicidal thoughts, plans, and behaviours and the utilization of health services following suicide attempts among community members. The very large diversity of the sociocultural settings coupled with the differences in health-care systems made it impossible to follow a very strictly uniform protocol. A minimum of rigour, however, was maintained following the best practice of descriptive anthropological/ ethnographic studies.

\section{METHOD}

A common survey instrument was developed, translated into the local languages, and pilottested by the research group. The participating sites of SUPRE-MISS represented all six WHO regions: Campinas (Brazil), Chennai (India), Colombo (Sri Lanka), Durban (South Africa), Hanoi (Viet Nam), Karaj (the Islamic Republic of Iran), and Tallinn (Estonia). Brisbane (Australia), Stockholm (Sweden), and Yuncheng (People's Republic of China) were also included, however, they only completed part of 
Table 1. Community survey: communities and target population

\begin{tabular}{llrrr}
\hline \hline Site & \multicolumn{1}{c}{ Community } & $\begin{array}{c}\text { Size of target } \\
\text { population }\end{array}$ & $\begin{array}{c}\text { Age range } \\
\text { (years) }\end{array}$ & $\begin{array}{c}\text { Sample } \\
\text { size }\end{array}$ \\
Campinas & Campinas city & 764400 & $>13$ & 516 \\
Chennai & South Chennai & 1380000 & $14-65$ & 500 \\
Colombo & Colombo Municipal Council area & 640020 & $>11$ & 684 \\
Durban & Durban functional region & 2000000 & $>5$ & 500 \\
Hanoi & Dong Da district & 350000 & $>9$ & 2280 \\
Karaj & Karaj & 900000 & $>13$ & 504 \\
Tallinn & Tallinn & 338560 & $>14$ & 500 \\
Yuncheng & Yuncheng county & 1200000 & $>17$ & 503 \\
Brisbane & Brisbane and Gold Coast & 2020570 & $>17$ & 13810 \\
Stockholm & Stockholm county & 1838882 & $>17$ & 50000 \\
\hline \hline
\end{tabular}

the original questionnaire (Yuncheng) or similar surveys (Brisbane and Stockholm). Assuming a lifetime prevalence of suicide attempts of $2.7 \%$ and a $95 \%$ CI of $1 \cdot 8-3 \cdot 6$, we aimed to randomly interview 500 community members at each of the SUPRE-MISS research sites. The protocol was approved by the respective ethics board in each country. All participants provided informed consent. The survey was conducted between 2002 and 2004.

\section{Sampling}

The catchment areas of the sites all covered urban areas, i.e. either the whole city (Campinas, Colombo, Durban, Karaj, Tallinn, Brisbane, Stockholm) or a sector of the city (South Chennai, Dong Da district of Hanoi), except for Yuncheng which covered a rural area. The size of the target population of the catchment area ranged between 350000 and 2000000 . The survey covered the general population of the respective community (Table 1).

In each site the most adequate source for sampling was chosen: In Campinas, Colombo, Yuncheng, and Stockholm the sampling frame was the list of residents of the census tracts, in Chennai, Durban, and Hanoi the street index, in Karaj the electric power company code, in Tallinn the general practitioners' lists, and in Brisbane the electronic version of the phone directory. The sampling strategies applied varied from simple random to multi-stage, cluster, and stratified sampling which are all probability sampling methods utilizing different types of random selection.

Refusals ranged from $0 \%$ to $7 \%$ with the exceptions of Durban, Brisbane, and Stockholm where refusals constituted $39 \%$ in each of the three cases. The reasons for refusals were mainly lack of interest or time.

\section{Interviewing}

The numbers of interviewers involved at each site ranged from 1 to 20 according to the site. The interviews were conducted by nurses, psychologists, medical students, medical doctors, family health workers, and public health professionals. All of them received formal training in the use of the survey instrument.

The interviews were mainly conducted faceto-face with the exception of Colombo and Stockholm where informants completed the survey themselves; in the latter the questionnaires were mailed to the respondents. In Brisbane, the interviews were carried out over the telephone. The face-to-face interviews usually took place at the respondent's home, but in Tallinn they were conducted at the general practitioner's office. Most of the interviews were conducted in private but due to local household arrangements it was impossible to avoid the presence of family members in some of the interviews conducted in Colombo, Chennai, Durban, Karaj, and Yuncheng.

\section{Instruments}

The instrument of the SUPRE-MISS community survey was based on the European Parasuicide Study Interview Schedule (EPSIS; Kerkhof et al. 1999), which had been applied in the WHO/EURO multicentre study on suicidal behaviour. In a meeting of experts the SUPREMISS instrument was discussed and refined. The final instrument (WHO, 2002) covered sociodemographic information, the history of suicidal behaviour, family data, physical health, 
Table 2. Socio-cultural indices of the SUPRE-MISS communities

\begin{tabular}{|c|c|c|c|c|c|c|c|c|}
\hline & Campinas & Chennai & Colombo & Durban & Hanoi & Karaj & Tallinn & Yuncheng \\
\hline Population & 1 million & $4 \cdot 2$ million & 642000 & 3 million & $2 \cdot 7$ million & $1 \cdot 2$ million & 400000 & $1 \cdot 1$ million \\
\hline \multirow{2}{*}{$\begin{array}{l}\text { Life expectancy } \\
\text { (years) }\end{array}$} & $F: 77$ & $F: 63$ & $F: 75$ & $F: 68$ & $\mathrm{~F}: 72$ & $\mathrm{~F}: 70$ & $F: 77$ & $\mathrm{~F}: 70$ \\
\hline & $M: 74$ & $M: 62$ & $\mathrm{M}: 71$ & $M: 62$ & $M: 67$ & $M: 68$ & $M: 65$ & $M: 68$ \\
\hline $\begin{array}{l}\text { Population } \\
\text { density }\left(/ \mathrm{km}^{2}\right)\end{array}$ & 1200 & 24000 & 17200 & 95 & 3000 & 900 & 2500 & 70 \\
\hline Main religion & Christianity & Hinduism & Buddhism & Christianity & None & Islam & Christianity & None \\
\hline \multirow{2}{*}{$\begin{array}{l}\text { Marriage } \\
\text { (mean age) }\end{array}$} & $F: 20$ & $F: 20$ & $F: 25$ & Not available & $F: 24$ & $\mathrm{~F}: 20$ & $F: 25$ & $F: 20$ \\
\hline & $\mathrm{M}: 28$ & $\mathrm{M}: 25$ & $M: 29$ & & $\mathrm{M}: 28$ & $M: 26$ & $\mathrm{M}: 28$ & $\mathrm{M}: 21$ \\
\hline $\begin{array}{l}\text { Schools } \\
\text { (per } 100000)\end{array}$ & 31 & 42 & 23 & 46 & 22 & 89 & 38 & Not available \\
\hline Literacy (\%) & 85 & 80 & 90 & 28 & 94 & 85 & 100 & 72 \\
\hline $\begin{array}{l}\text { Unemployment } \\
(\%)\end{array}$ & 14 & 10 & 8 & 38 & 8 & 24 & 10 & 8 \\
\hline $\begin{array}{l}\text { Below the } \\
\text { poverty line }\end{array}$ & $12 \%$ & $32 \%$ & $6 \%$ & $\begin{array}{l}1-61 \% \\
\text { (as per ethnic } \\
\text { group) }\end{array}$ & $10 \%$ & Not available & $17 \%$ & $9 \%$ \\
\hline $\begin{array}{l}\text { Psychiatrists } \\
\text { (per } 100000 \text { ) }\end{array}$ & 21 & 3 & 4 & 1 & 2 & 1 & 13 & 1 \\
\hline $\begin{array}{l}\text { Emergency } \\
\text { service }^{\mathrm{a}}\end{array}$ & 1 & 1 & None & 1 & 1 & None & 2 & None \\
\hline Suicide rate ${ }^{\mathrm{b}}$ & 4 & 17 & 46 & 17 & 1 & 6 & 34 & $23^{\mathrm{c}}$ \\
\hline
\end{tabular}

a Emergency telephone line or service for suicide.

b Average for both sexes combined during the past 10 years for which information was available (per 100000 ).

c In selected rural areas of China, 1999.

contact with health services, mental health, questions related to substance use, and to community stress and problems.

To assess suicidal behaviour, the following questions were asked:

(1) 'Have you ever seriously thought about committing suicide?'

(2) 'Have you ever made a plan for committing suicide?'

(3) 'Have you ever attempted suicide?'

Further questions were asked, if the answer was 'yes' to any of these questions.

A separate instrument was specifically designed to describe the socio-cultural context of the sites: that is, the community description component of SUPRE-MISS. The instruments were translated into the local languages of the sites and adapted to take into account cultural specificities. The content and face validity of the questionnaire were evaluated in the pilot studies.

\section{RESULTS}

\section{Description of the community}

\section{Socio-cultural indices}

The sites differed substantially from each other with regards to their socio-cultural characteristics (Table 2).

\section{Perception of suicide and ascertainment of suicide}

The prevailing perception of suicide in general, and the feelings and reactions towards a person who commits suicide varied by site, as well as the ascertainment of suicide, which is conducted in different ways in each place (Table 3 ). The ambivalence felt towards a suicide victim was also true for a person who attempted suicide (anger/criticism and support) and the family members of the suicide victim, who was sometimes also confronted with distrust, avoidance and blame for being partly responsible.

\section{Community survey}

\section{Socio-demographic characteristics}

Except for the sites of Chennai and Yuncheng, more than half of the respondents were female in each site (Table 4). One male in Campinas and one male in Hanoi stated themselves to be transsexual.

Tallinn and Yuncheng had the highest mean age (42.7 and 42.6 years) and the lowest was found in Chennai (27.1 years). The age of the respondents ranged between 6 (Durban) and 96 years (Hanoi) (Table 4).

Except for Chennai and Durban, more than half of the respondents were married or living 
Table 3. Prevailing perceptions of suicide, feelings and reactions towards the suicide victim, and ascertainment of suicide in SUPRE-MISS communities

\begin{tabular}{|c|c|c|c|}
\hline & Suicide in general & Suicide victim & $\begin{array}{l}\text { Ascertainment } \\
\text { of suicide }\end{array}$ \\
\hline Campinas & $\begin{array}{l}\text { Condemned (mental illness, moral } \\
\text { weakness, spiritual problems) }\end{array}$ & Pity, moral condemnation & $\begin{array}{l}\text { Police, forensic } \\
\text { physician }\end{array}$ \\
\hline Chennai & $\begin{array}{l}\text { Inconsistent (impulsive act, } \\
\text { social not health problem) }\end{array}$ & $\begin{array}{l}\text { Anger, rejection, sympathetic if social } \\
\text { reasons, brought shame }\end{array}$ & $\begin{array}{l}\text { Police, district } \\
\text { administration }\end{array}$ \\
\hline Colombo & $\begin{array}{l}\text { Not seen positively (some support, if } \\
\text { ritualized as political weapon) }\end{array}$ & $\begin{array}{l}\text { Sympathy, extreme misfortune of } \\
\text { personal nature, brought shame }\end{array}$ & Coroner \\
\hline Durban & $\begin{array}{l}\text { Not seen positively (mental illness, } \\
\text { social problems, spiritually } \\
\text { unacceptable) }\end{array}$ & Sympathy, condemnation, criticism & Forensic expert \\
\hline Hanoi & $\begin{array}{l}\text { Condemned (not meeting } \\
\text { responsibilities in life, weak) }\end{array}$ & Sympathy, condemnation, criticism & $\begin{array}{l}\text { No specific } \\
\text { procedure }\end{array}$ \\
\hline Karaj & $\begin{array}{l}\text { Sin, behavioural issue (lack of belief, } \\
\text { daily life stress), kept secret }\end{array}$ & Anger, sympathy, condemnation & Forensic physician \\
\hline Tallinn & $\begin{array}{l}\text { Irresponsible egoistic act (accepted if } \\
\text { serious somatic illness) }\end{array}$ & $\begin{array}{l}\text { Compassion, ambivalence } \\
\text { (weakness/strength) }\end{array}$ & $\begin{array}{l}\text { Police, forensic } \\
\text { expert }\end{array}$ \\
\hline Yuncheng & $\begin{array}{l}\text { Not seen positively (social not health } \\
\text { problem) }\end{array}$ & $\begin{array}{l}\text { Sympathy (unless done to atone for } \\
\text { socially unacceptable behaviour, e.g. } \\
\text { theft, drug abuse) }\end{array}$ & $\begin{array}{l}\text { Local health } \\
\text { providers }\end{array}$ \\
\hline
\end{tabular}

Table 4. Socio-demographic variables (in \%, rounded) of the SUPRE-MISS communities

\begin{tabular}{|c|c|c|c|c|c|c|c|c|}
\hline & Campinas & Chennai & Colombo & Durban & Hanoi & Karaj & Tallinn & Yuncheng \\
\hline Sex & $(n=516)$ & $(n=500)$ & $(n=675)$ & $(n=500)$ & $(n=2280)$ & $(n=504)$ & $(n=500)$ & $(n=503)$ \\
\hline Male & 39 & 68 & 47 & 46 & 48 & 37 & 49 & 51 \\
\hline Female & 61 & 32 & 53 & 54 & 52 & 63 & 51 & 49 \\
\hline $\begin{array}{l}\text { Age (mean) } \\
\text { (years) }\end{array}$ & $\begin{array}{c}(n=516) \\
42\end{array}$ & $\begin{array}{c}(n=500) \\
27\end{array}$ & $\begin{array}{c}(n=655) \\
40\end{array}$ & $\begin{array}{c}(n=500) \\
39\end{array}$ & $\begin{array}{c}(n=2257) \\
40\end{array}$ & $\begin{array}{c}(n=503) \\
29\end{array}$ & $\begin{array}{c}(n=500) \\
43\end{array}$ & $\begin{array}{c}(n=503) \\
43\end{array}$ \\
\hline Marital status & $(n=516)$ & $(n=500)$ & $(n=655)$ & $(n=499)$ & $(n=2277)$ & $(n=504)$ & $(n=500)$ & $(n=503)$ \\
\hline Single & 29 & 72 & 27 & 52 & 34 & 44 & 25 & 7 \\
\hline Married & 55 & 27 & 60 & 33 & 63 & 54 & 58 & 92 \\
\hline Widowed & 7 & 0 & 13 & 12 & 2 & 1 & 8 & 1 \\
\hline Divorced & 9 & 0 & 1 & 4 & 1 & 1 & 9 & 0 \\
\hline Education & $(n=515)$ & $(n=500)$ & $(n=650)$ & $(n=496)$ & $(n=2274)$ & $(n=503)$ & $(n=498)$ & $(n=503)$ \\
\hline None & 13 & 0 & 5 & 23 & 2 & 2 & 0 & 19 \\
\hline Primary & 26 & 46 & 21 & 36 & 8 & 10 & 9 & 43 \\
\hline Secondary & 16 & 13 & 64 & 21 & 21 & 20 & 26 & 36 \\
\hline Higher & 30 & 14 & 7 & 11 & 50 & 49 & 36 & 0 \\
\hline University & 15 & 26 & 1 & 9 & 18 & 18 & 28 & 1 \\
\hline Other & 0 & 0 & 1 & 0 & 2 & 0 & 1 & 0 \\
\hline Religion & $(n=516)$ & $(n=500)$ & $(n=683)$ & $(n=497)$ & $(n=2277)$ & $(n=504)$ & $(n=498)$ & $(n=503)$ \\
\hline Christian $^{\mathrm{a}}$ & 86 & 3 & 13 & 40 & 3 & 0 & 47 & 1 \\
\hline Muslim & 0 & 5 & 24 & 3 & 0 & 100 & 0 & 0 \\
\hline Hindu & 0 & 92 & 18 & 13 & 0 & 0 & 0 & 0 \\
\hline Buddhist & 0 & 0 & 44 & 0 & 6 & 0 & 0 & 1 \\
\hline Other ${ }^{\mathrm{b}}$ & 5 & 0 & 1 & 28 & 1 & 0 & 3 & 0 \\
\hline None & 8 & 0 & 0 & 17 & 91 & 0 & 49 & 98 \\
\hline Religiousness & $(n=514)$ & $(n=499)$ & $(n=659)$ & $(n=484)$ & $(n=2106)$ & $(n=502)$ & $(n=492)$ & $(n=503)$ \\
\hline Yes & 91 & 92 & 96 & 51 & 34 & 80 & 37 & No data \\
\hline
\end{tabular}

a Christian includes Catholic, Protestant, Greek Orthodox (25\% in Tallinn).

b Other includes Kardecist (4\% in Campinas), Jewish (10\% in Durban), Shembe (4\% in Durban), etc.

with a permanent partner. Almost three quarters were single in Chennai (72.2\%) (Table 4).

In Hanoi, Karaj and Tallinn two thirds of the sample were characterized by having completed higher (i.e. non-university higher education) or university education. In Campinas and Chennai this was the case for slightly less than half of the respondents. In Colombo, the majority had completed secondary education and in Durban and Yuncheng primary education (Table 4). 
Table 5. Lifetime suicide ideation, plans and attempts, and medical attention (in \%, rounded) following the first suicide attempt

\begin{tabular}{|c|c|c|c|c|c|c|c|c|c|c|c|}
\hline \multirow[b]{2}{*}{ Site } & \multicolumn{2}{|c|}{ Thoughts $(\mathrm{T})^{\mathrm{a}}$} & \multicolumn{2}{|c|}{ Plans $(\mathrm{P})^{\mathrm{b}}$} & \multicolumn{2}{|c|}{ Attempts $(\mathrm{A})^{\mathrm{c}}$} & \multirow{2}{*}{$\begin{array}{l}\mathrm{A}: \mathrm{P} \\
\text { ratio }\end{array}$} & \multirow{2}{*}{$\begin{array}{l}\mathrm{A}: \mathrm{T} \\
\text { ratio }\end{array}$} & \multirow{2}{*}{$\begin{array}{l}\mathrm{P}: \mathrm{T} \\
\text { ratio }\end{array}$} & \multicolumn{2}{|c|}{ Medical attention } \\
\hline & $n$ & Yes $(\%)$ & $n$ & Yes $(\%)$ & $n$ & Yes $(\%)$ & & & & $n$ & Yes $(\%)$ \\
\hline Campinas & 516 & $18 \cdot 6$ & 516 & $5 \cdot 2$ & 516 & $3 \cdot 1$ & $1: 1 \cdot 7$ & $1: 6 \cdot 0$ & $1: 3 \cdot 6$ & 16 & 38 \\
\hline Chennai & 500 & $2 \cdot 6$ & 500 & $2 \cdot 0$ & 500 & $1 \cdot 6$ & $1: 1 \cdot 3$ & $1: 1 \cdot 6$ & $1: 1 \cdot 3$ & 8 & 88 \\
\hline Colombo & 670 & $7 \cdot 3$ & 678 & $1 \cdot 5$ & 675 & $2 \cdot 1$ & $1: 0 \cdot 7$ & $1: 3 \cdot 5$ & $1: 4 \cdot 9$ & 9 & 56 \\
\hline Durban & 500 & $25 \cdot 4$ & 500 & $15 \cdot 6$ & 500 & $3 \cdot 4$ & $1: 4 \cdot 6$ & $1: 7 \cdot 5$ & $1: 1 \cdot 6$ & 17 & 47 \\
\hline Hanoi & 2266 & $8 \cdot 9$ & 2267 & $1 \cdot 1$ & 2267 & $0 \cdot 4$ & $1: 2 \cdot 8$ & $1: 22 \cdot 3$ & $1: 8 \cdot 1$ & 9 & 22 \\
\hline Karaj & 504 & $14 \cdot 1$ & 504 & $6 \cdot 7$ & 504 & $4 \cdot 2$ & $1: 1 \cdot 6$ & $1: 3 \cdot 4$ & $1: 2 \cdot 1$ & 21 & 48 \\
\hline Tallinn & 498 & $12 \cdot 4$ & 497 & $5 \cdot 4$ & 497 & $3 \cdot 6$ & $1: 1 \cdot 5$ & $1: 3 \cdot 4$ & $1: 2 \cdot 3$ & 18 & 39 \\
\hline Yuncheng & 503 & $18 \cdot 5$ & 503 & $7 \cdot 4$ & 503 & $2 \cdot 4$ & $1: 3 \cdot 1$ & $1: 7 \cdot 7$ & $1: 2 \cdot 5$ & 12 & 75 \\
\hline Brisbane & 8794 & $11 \cdot 0$ & 6235 & $10 \cdot 6$ & 11553 & $4 \cdot 2$ & $1: 2 \cdot 5$ & $1: 2 \cdot 6$ & $1: 1 \cdot 0$ & No data & \\
\hline Stockholm & No data & & 30243 & $15 \cdot 5$ & 30310 & $4 \cdot 0$ & $1: 3 \cdot 9$ & & & 1221 & 55 \\
\hline
\end{tabular}

\footnotetext{
a 'Have you ever seriously thought about committing suicide?'

b 'Have you ever made a plan for committing suicide?'

c 'Have you ever attempted suicide?'
}

Whereas there was one predominant religion (i.e. religious denomination) in many of the sites, it was not always reflected in the perceived religiousness of the respondents, which had been operationalized by the question 'Do you consider yourself to be a religious person?' In Campinas and Chennai, the respondents were predominantly Christian and Hindu respectively; they also considered themselves to be religious persons. In Colombo, there was a mixture of several religions and the respondents still considered themselves as religious persons. Durban also had a variety of religious denominations, however the perceived religiousness was lower. In Tallinn, there was a mixture of Christian and no religion, and the religiousness was even lower. In Karaj, Islam was predominant at $100 \%$, however, not everyone thought of themselves as a religious person. In Hanoi, the large majority did not have a religious denomination; however, a number of people considered themselves as being religious (Table 4).

\section{Physical and mental health}

The sites varied strongly with regards to selfreported physical and mental health (these items were not answered in Yuncheng). The lowest number of respondents indicating a longstanding physical illness or disability was found in Chennai $(3.8 \%)$ and the highest in Campinas $(41.5 \%)$. The experience of mental problems varied widely as well, from $0.8 \%$ (Chennai) to $35.3 \%$ (Karaj). Karaj was the only site where the level of self-reported mental problems was higher than the one of physical illness.

Of those who reported the use of alcoholic beverages in the past 3 months, the highest daily intake was observed, almost equally in Colombo $(20 \cdot 2 \%)$, Hanoi $(20 \cdot 1 \%)$, and Chennai $(18 \cdot 3 \%)$. When combining the daily and weekly use, the intake became most prominent in Durban $(59 \cdot 1 \%)$.

\section{Suicide attempts, plans and ideation}

Since at the time the SUPRE-MISS community survey was being carried out similar surveys were being conducted in Brisbane and Stockholm, results from these surveys were included in Table 5. In Stockholm, the questions were asked in a slightly different way. Those for thoughts and plans about suicide had been combined and read 'Have you ever come to such a situation that you considered seriously to take your own life, or even made a plan to do so?' The question for attempted suicide was 'Have you ever attempted to take your own life?'

The highest rates of lifetime suicidal thoughts and suicide plans in the community were found in Durban (25.4\% and 15.6\%), whereas Karaj and Brisbane had the highest rate of lifetime suicide attempts $(4.2 \%$ in both cases). A particularly low rate of suicide attempts was found among the respondents in the site of Hanoi $(0.4 \%)$. The rates of suicide thoughts, plans and attempts varied between the lowest and the highest rate across sites by a factor of $9 \cdot 8,14 \cdot 2$, 
and 10.5 respectively, e.g. Karaj had 10.5 times more suicide attempts reported than Hanoi (Table 5).

The relation between suicide thoughts, plans, and attempts revealed particularly interesting results. Depending on the site, suicidal thinking could be up to 22 times (Hanoi) more frequent in a specific site than the actual attempts reported by respondents. Making a plan for committing suicide could be five times more frequent (Durban) than an attempt. However, in some sites, thoughts about suicide, plans and attempts were very close to each other. In Chennai, for instance, thoughts of suicide were less than twice as frequent and plans almost as frequent as attempts. The extreme was Colombo where less plans were made than actual suicide attempts (Table 5).

\section{Medical attention following a suicide attempt and seriousness of the attempt}

Those respondents who reported one or more suicide attempts, were asked whether their first suicide attempt required medical attention or hospital admission. Between 22.2\% (Hanoi) and $87.5 \%$ (Chennai) reported medical attention following an attempt (Table 5).

Based on the self-evaluation of seriousness, more serious suicide attempts were made in Chennai $(75 \cdot 0 \%)$, Hanoi $(55.6 \%)$ and Tallinn $(55.6 \%)$, whereas in Karaj more answers indicating a 'cry for help' $(61.9 \%)$ were reported. It is difficult to draw definite conclusions as the results are based on self-reports of one single interview.

\section{DISCUSSION}

The SUPRE-MISS community component was an effort to collect data on suicidal thoughts, plans of suicide and suicide attempts from communities characterized by different sociocultural backgrounds around the world. As such, it is the first of its kind on two grounds: (i) This paper presents the study, for the very first time, introducing the unique characteristics of each participating community, revealing the range of information obtained and highlighting key observations made. (ii) Moreover, for some sites, it was the first time that data on suicidal behaviours had been collected, particularly on such a large scale. SUPRE-MISS was an opportunity not only to give visibility to the burden of suicidal behaviours, but also to initiate research on suicidal behaviours in many of these places.

Numerous difficulties of a logistic and methodological nature had to be tackled, and the present data will have to undergo rigorous and critical appraisal before any attempt can be made to specifically address the issues of comparing the results among the participating sites or to those of other studies, or of making generalizations of the results.

However, all participating sites of the community survey employed probability samples which were as representative as possible of the catchment area of the emergency-care departments (where the intervention study component was conducted). However, some deviations from what could be otherwise expected from a random distribution were found: the large number of respondents with a university education (e.g. Hanoi) or of single respondents (e.g. Chennai), reflects unique characteristics of the particular catchment area in question. The imbalanced gender ratio in Chennai could be explained by societal norms which requested the male and more educated family members to answer questions, thus confounding the sampling. In Karaj, the community sample was matched with the respondents from the intervention study component of the emergency departments, where the majority was female. In Campinas, where more women usually stay at home than men, the imbalanced gender ratio might reflect that in the absence of the individual selected, the interview was conducted with the person available at the household at the time of the interview. However, the interviewers had been explicitly trained not to do so and a possible explanation is that the interview situations took into account the practicability in each site. If, in some instances, family members were present, the local cultural reality had to be respected and we are aware of the potential distortion of the data; nevertheless, we stress that this is the first time ever that this type of data was collected from these places.

Although the prevalence of thoughts, plans and attempts of suicide varied across the samples, most of the results were within the ranges of previously published data on community surveys in different places; the 
exceptions were Durban which had a particularly high rate of lifetime suicidal thoughts $(25.4 \%)$ and Hanoi which had a particularly low rate of lifetime suicide attempts $(0.4 \%)$. Generally, thoughts of suicide were more frequent than plans, which were more frequent than attempts. However, in Colombo there were more reported suicide attempts than plans.

Setting aside methodological deliberations, we are nevertheless confronted with cultural influences and the subject of suicide as value laden. Some of the differences across sites were most probably affected by differences in the willingness of respondents from different cultures to report suicidal thoughts, suicide plans, and attempts. There might not only be differences in openly discussing suicidal behaviours, but also in the awareness about them.

The most striking findings concerned the interrelation of suicidal thoughts, suicide plans and attempts. Site-specific differences in the prevalence of suicidal thoughts, plans and attempts suggest the need for different, site-specific approaches to suicide prevention: in Hanoi one should perhaps focus prevention activities on those with suicide plans (because suicidal thoughts are 22 times more common than suicide attempts while suicide plans are only three times more common); in Chennai it would be more appropriate to focus prevention on those who express suicidal thoughts with or without a plan (because suicidal thoughts are only three times more common than suicide attempts); and in Colombo many attempts are made without developing a specific suicide plan, to such an extent that novel approaches that focus on other warning signs of suicide attempts are needed. This is true in particular for Tallinn, where an alarming $28 \%$ of those who attempted suicide did not indicate to have ever had thoughts about committing suicide or to ever have made a plan. Suicidal behaviour in the absence of a suicide plan has been reported previously in China (Phillips et al. 2002a,b), even though it was not confirmed in this sample from China.

The finding that in all but two sites less than half of the persons who attempted suicide received medical attention is concordant with the limited published data on this issue (Centers for Disease Control, 1991; Schweitzer et al. 1995; Kjoller \& Helweg-Larsen, 2000; Ramberg \& Wasserman, 2000; Kuo et al. 2001; Pirkis et al. 2001; Bille-Brahe \& Löhr, 2004). Whether help is sought following a suicide attempt depends on the severity of the injury, on the availability, accessibility and quality of healthcare services, and on the fear of possible negative consequences: stigmatization of seeking care, as well as involvement with criminal justice.

Different levels of perceived stigmatization may also have affected responses to questions about physical illness, mental illness and alcohol use and, thus, explain some of the observed differences across the sites. The way mental illness is understood in different cultures and the particular difficulty of grasping it should also be taken into account for interpretation, in spite of the efforts to capture these culture-specific meanings in the translation and adaptation of the instrument. However, the overall results need to be further explored in a careful analysis of the complete questionnaire, a work that is under way.

The information collected with regards to the religious denomination of the respondents and their religiousness opens up an area of research which enters quite uncharted territory. Few authors have investigated the influence of religion on suicide (Neeleman, 1998; Kelleher et al. 1998). Bertolote \& Fleischmann (2002) discussed the importance of the religious context and the prevalence of a religion in a country as major cultural factors in the determination of suicide. There are some indications that the religiousness of a person might serve as a protective factor against suicide. The data collected in the SUPRE-MISS study, of which only a portion is presented here, will allow a more thorough exploration of this issue.

Finding ways of identifying those persons in the community whose suicide attempt remains undetected poses a major challenge. It is hoped that a more detailed analysis of the SUPREMISS data will reveal some characteristics of this specific population and suicide risk factors in different cultures.

\section{ACKNOWLEDGEMENTS}

The study was funded by the Department of Mental Health and Substance Abuse, World Health Organization, where both first authors are employed. Some field research sites obtained 
additional funding from the following agencies: Hanoi: Swedish International Cooperation Development Agency (SIDA), Stockholm, Sweden [within the collaboration between the Swedish National and Stockholm County Council's Centre for Suicide Research and Prevention of Mental Ill-Health (NASP) at the Institute for Psychosocial Medicine (IPM) and the Department of Public Health Sciences at the Karolinska Institute and Hanoi Medical University]. Karaj: Iran National Research Center for Medical Sciences, Tehran, Iran. Tallinn: Estonian Health Insurance Fund, Tallinn, Estonia; the Swedish National and Stockholm County Council's Centre for Suicide Research and Prevention of Mental Ill-Health (NASP) at the Institute for Psychosocial Medicine (IPM) and the Department of Public Health Sciences at the Karolinska Institute, Stockholm, Sweden. Yuncheng: Community data was collected as part of the 'Attitudes and Cultural Meanings of Suicide in Contemporary Chinese Society' study (PI: Professor Singlee) funded by the Research Grants Council of Hong Kong.

\section{DECLARATION OF INTEREST}

None.

\section{REFERENCES}

Bertolote, J. M. \& Fleischmann, A. (2002). A global perspective in the epidemiology of suicide. Suicidologi 2, 6-8.

Bille-Brahe, U. \& Löhr, C. (2004). Suicide attempters, health care systems, and the quality of treatments. In Suicidal Behaviour: Theories and Research Findings (ed. D. De Leo, U. Bille-Brahe, A. Kerkhof and A. Schmidtke). Hogrefe and Huber: Göttingen.

Centers for Disease Control (1991). Attempted suicide among high school students - United States, 1990. Journal of the American Medical Association 266, 1911-1912.

Kelleher, M. J., Chambers, D., Corcoran, P., Williamson, E. \& Keeley, H. S. (1998). Religious sanctions and rates of suicide worldwide. Crisis 19, 78-86.

Kerkhof, A., Bernasco, W., Bille-Brahe, U., Platt, S. \& Schmidtke, A. (1999). European Parasuicide Study Interview Schedule (EPSIS). In Facts and Figures: WHO/EURO (ed. U. Bille-Brahe). WHO Regional Office for Europe: Copenhagen.

Kessler, R. C., Borges, G. \& Walters, E. E. (1999). Prevalence of and risk factors for lifetime suicide attempts in the National Comorbidity Survey. Archives of General Psychiatry 56, 617-626.
Kjoller, M. \& Helweg-Larsen, M. (2000). Suicidal ideation and suicide attempts among adult Danes. Scandinavian Journal of Public Health 28, 54-61.

Kuo, W. H., Gallo, J. J. \& Tien, A. Y. (2001). Incidence of suicide ideation and attempts in adults: the 13-year follow-up of a community sample in Baltimore, Maryland. Psychological Medicine 31, 1181-1191.

Meltzer, H., Lader, D., Corbin, T., Singleton, N., Jenkins, R. \& Brugha, T. (2002). Non-fatal Suicidal Behaviour among Adults Aged 16 to 74 in Great Britain. National Statistics: London.

Moscicki, E. K. (1989). Epidemiologic surveys as tools for studying suicidal behavior: a review. Suicide and Life Threatening Behavior 19, 131-147.

Neeleman, J. (1998). Regional suicide rates in the Netherlands: does religion still play a role? International Journal of Epidemiology 27, 466-472.

Paykel, E. S., Myers, J. K., Lindenthal, J. J. \& Tanner, J. (1974). Suicidal feelings in the general population: a prevalence study. British Journal of Psychiatry 124, 460-469.

Phillips, M. R., Li, X. \& Zhang, Y. (2002a). Suicide rates in China, 1995-99. Lancet 359, 835-840.

Phillips, M. R., Yang, G., Zhang, Y., Wang, L., Ji, H. \& Zhou, M. $(2002 b)$. Risk factors for suicide in China: a national case-control psychological autopsy study. Lancet 360, 1728-1736.

Pirkis, J., Burgess, P. \& Dunt, D. (2000). Suicidal ideation and suicide attempts among Australian adults. Crisis 21, 16-25.

Pirkis, J. E., Burgess, P. M., Meadows, G. N. \& Dunt, D. R. (2001). Suicidal ideation and suicide attempts as predictors of mental health service use. Medical Journal of Australia 175, 542-545.

Platt, S., Bille-Brahe, U., Kerkhof, A., Schmidtke, A., Bjerke, T., Crepet, P., De Leo, D., Haring, C., Lonnqvist, J., Michel, K., Philippe, A., Pommereau, X., Querejeta, I., Salander-Renberg, E., Temesvary, B., Wasserman, D. \& Sampaio-Faria, J. G. (1992). Parasuicide in Europe: the WHO/EURO multicentre study on parasuicide. I. Introduction and preliminary analysis for 1989 Acta Psychiatrica Scandinavica 85, 97-104.

Ramberg, I. L. \& Wasserman, D. (2000). Prevalence of reported suicidal behaviour in the general population and mental healthcare staff. Psychological Medicine 30, 1189-1196.

Schmidtke, A., Bille-Brahe, U., De Leo, D., Kerkhof, A. (eds). (2004). Suicidal Behaviour in Europe: Results from the WHO/EURO Multicentre Study on Suicidal Behaviour. Hogrefe and Huber: Göttingen.

Schwab, J. J., Warheit, G. J. \& Holzer, C. E. (1972). Suicidal ideation and behavior in a general population. Diseases of the Nervous System 33, 745-748.

Schweitzer, R., Klayich, M. \& McLean, J. (1995). Suicidal ideation and behaviours among university students in Australia. Australian and New Zealand Journal of Psychiatry 29, 473-479.

Weissman, M. M., Bland, R. C., Canino, G. J., Greenwald, S., Hwu, H. G., Joyce, P. R., Karam, E. G., Lee, C. K., Lellouch, J., Lepine, J. P., Newman, S. C., Rubio-Stipec, M., Wells, J. E., Wickramaratne, P. J., Wittchen, H. U. \& Yeh, E. K. (1999). Prevalence of suicide ideation and suicide attempts in nine countries. Psychological Medicine 29, 9-17.

Welch, S. S. (2001). A review of the literature on the epidemiology of parasuicide in the general population. Psychiatric Services 52, 368-375.

WHO (2002). Multisite Intervention Study on Suicidal Behaviours SUPRE-MISS : Protocol of SUPRE-MISS. World Health Organization: Geneva.

WHO (2003). The World Health Report 2003: Shaping the Future. World Health Organization: Geneva. 